\title{
Editorial
}

\section{Changing Epidemiological and Clinical pattern of Dengue in Bangladesh 2018}

\author{
Quazi Tarikul Islam ${ }^{1}$
}

\begin{abstract}
(c) (1) (2)
DOI: http://dx.doi.org/I0.3329/jom.v20il.388/2

Copyright: (C) 2019 Islam QT. This is an open access article published under the Creative Commons Attribution-NonCommercial-NoDerivatives 4.0 International License, which permits use, distribution and reproduction in any medium, provided the original work is properly cited, is not changed in any way and it is not used for commercial purposes.
\end{abstract}

Received: 09 November, 2018;

Accepted: 29 November, 2018

Dengue is the most rapidly spreading mosquito-borne viral disease in the world. In the last 50 years, incidence has increased 30-fold with increasing geographic expansion to new countries and, in the present decade, from urban to rural settings. An estimated 50 million dengue infections occur annually and approximately 2.5 billion people live in dengue endemic countries. ${ }^{1}$

The 2002 World Health Assembly resolution WHA55.17 2 urged greater commitment to dengue by WHO and its Member States. Of particular significance is the 2005 World Health Assembly resolution WHA58.3 on the revision of the International Health Regulations (IHR) ${ }^{3}$, which includes dengue as an example of a disease that may constitute a public health emergency of international concern with implications for health security due to disruption and rapid epidemic spread beyond national borders.

Some 1.8 billion (more than $70 \%$ ) of the population at risk for dengue worldwide live in member states of the WHO SouthEast Asia Region and Western Pacific Region, which bear nearly $75 \%$ of the current global disease burden due to dengue. The Asia Pacific Dengue Strategic Plan for both regions (2008 - 2015) has been prepared in consultation with member countries and development partners in response to the increasing threat from dengue, which is spreading to new geographical areas and causing high mortality during the early phase of outbreaks. The strategic plan aims to aid countries to reverse the rising trend of dengue by enhancing their preparedness to detect, characterize and contain outbreaks rapidly and to stop the spread to new areas.

1. Editor in chief, National Guideline for Clinical Management of Dengue Syndrome 2018.

Corresponding author: Professor Quazi Tarikul Islam, Editor in chief, National Guideline for Clinical Management of Dengue Syndrome 2018, Bangladesh. E-mail: prof.tarik@gmail.com.
Since 2000, epidemic dengue has spread to new areas and has increased in the already affected areas of the region. In 2003, eight countries - Bangladesh, India, Indonesia, Maldives, Myanmar, Sri Lanka, Thailand and Timor-Leste reported dengue cases. In 2004, Bhutan reported the country's first dengue outbreak. In 2005, WHO's Global Outbreak Alert and Response Network (GOARN) responded to an outbreak with a high case-fatality rate $(3.55 \%)$ in TimorLeste. In November 2006, Nepal reported indigenous dengue cases for the first time. The Democratic Peoples' Republic of Korea is the only country of the South-East Region that has no reports of indigenous dengue.

Bangladesh first experience a large outbreak of Dengue in the year 2000 with 5551 cases and case fatality of 93 . The containment of the disease was successfully handled after word and was rewarding. Even between the year 2007 to 2011 there were very lower number of cases reported with no death record. From 2015 the incidence of cases started rising with few death. This is obviously a change in epidemiology of disease.

The pathogenesis of severe dengue is particularly intriguing with the involvement of different immune factors. Also, the epidemiology of dengue in South East Asia is undergoing a change in the human host, the dengue virus and the vector bionomics. $^{4}$

Shift in affected age groups, sex differences and expansion to rural areas are evident, while the virulence and genotype of the virus determine the severity and time interval between sequential infections. The Aedes mosquito, a potent and adaptive vector, has evolved in longevity and survival, affected by seasonality and climate variability, socio cultural and economic factors of human habitation and development.

Dengue fever (DF) and its severe form, the dengue haemorrhagic fever (DHF), is a re emerging arboviral disease 
of great public health importance, and it has spread to all tropical and sub tropical countries in the world. All serotypes/ genotypes are now circulating globally and maintaining hyperendemicity. 3,5

\section{Pathogenesis:}

DHF occurs in a small proportion of dengue patients, mostly in those with secondary infection and is characterized by an increased vascular permeability that results in plasma leakage, contracted intravascular volume and shock in severe cases. The leakage is unique as it is selective in pleural and peritoneal cavities with 24-48 h. Rapid recovery of shock without sequel and the absence of inflammation in the pleura and peritoneum indicate functional changes in the vascular integrity rather than in the structural damage of the endothelium as the underlying mechanism. ${ }^{6}$

The epidemiology of DF/DHF is complex and remains poorly understood. It involves host, viral and vector status that are further influenced by demographic, economic, behavioral and varied societal factors. Many field observations have raised questions against widely accepted epidemiological characteristics of dengue. ${ }^{2,6}$ It is thus imperative to properly understand the evolving pattern and trend of DF/DHF epidemiology, as it is crucial in determining the success of prevention and control programmes.

\section{Changes in the dengue virus:}

a. Virulence affecting severity of the disease

Sequential infections or secondary infections are important to determine the severity of the disease. The infection enhancement contributes to the pattern of variable sized outbreaks observed. Studies in Thailand have revealed the following quantum of DHF risk with different sequences of dengue viruses with DENV 1/ DENV 2: 500 fold, DENV 3/DENV 2: 150 fold and DENV 4/DENV 2 equals to 50 fold risk. ${ }^{7}$

b. Genotype affecting time interval between sequential infections.

\section{Changes in the vector bionomics:}

a. Rural spread

b. Changing pattern of dengue transmission

c. Seasonality and climate variability

d. Sociocultural and socioeconomic factors affecting vector longevity and survival.

In 2018 Bangladesh experienced an unusual outbreak of Dengue with highest incidence of recorded cases. The presentation of DHF were much more than any previous years. Special observations were

- Less rash

- More Leucopenia
- High AST

- Tourniquet test +ve early

- Diarrhea

- Pharyngeal congestion

- Ascites/ pleural effusion

- Myocarditis

Effective dengue prevention and control is a difficult effort today than ever before. However, first step would be recognizing it as a priority and understanding its characteristics. ${ }^{8}$ The factors that may have contributed to rapid changing epidemiology of DF/ DHF in South East Asia region are the challenges that need to be addressed in designing operational research and implementation strategies. Operational research is needed to answer research questions on how the efficacy, cost effectiveness, sustainability and scaling up of existing and promising new control methods can be enhanced.

The major factors influencing changes in dengue Epidemiology and clinical presentations include: i) viral genotypes/subtypes with increased virulence; ii) lack of information on human population genetics and its relation with viral genome; iii) lack of information on vector ecology in micro climatic conditions; iv) viral load injected by infected mosquito; v) post infection natural immunity of the host and vi) time interval in sequential infection.

This year 2018 we have new national guideline on clinical management of Dengue Syndrome. Web link: http:// www.dghs.gov.bd/images/docs/Publications/National GuidelineforDengue2018.pdf

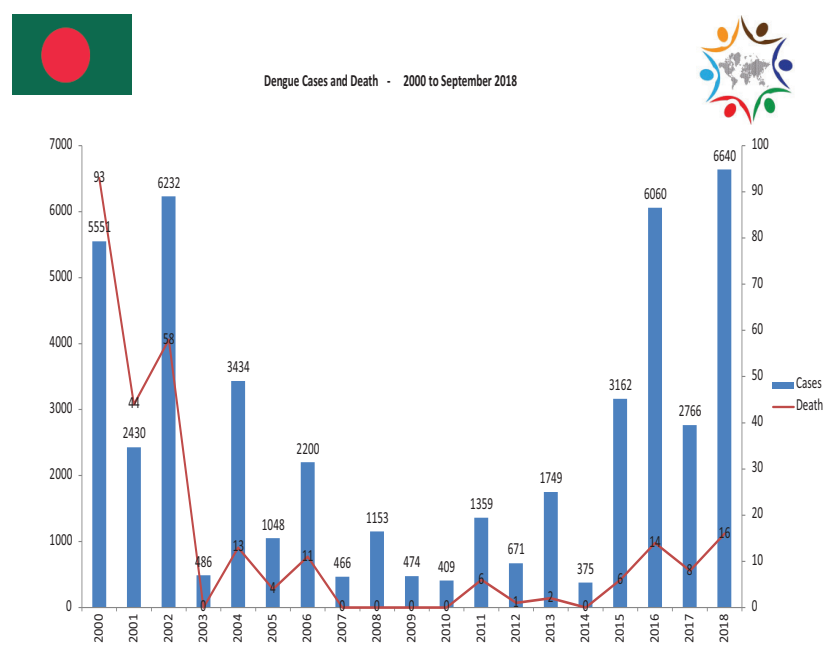

Figure: Dengue cases and death in Bangladesh (From 2000 to September 2018)

Conflicts of interest: None. 


\section{References:}

1. World Health Organization. Global strategy for dengue prevention and control 2012-2020. Geneva: WHO, 2012. Available from: http://apps.who.int/iris/bitstream/10665/ 75303/1/9789241504034_eng.pdf[Last accessed on 15 Oct 2018].

2. Guha Sapir D, Schimmer B. Dengue fever: New paradigms for a changing epidemiology. Emerg Themes Epidemiol 2005;2:1. https://doi.org/10.1186/1742-7622-2-1

3. Rodhain F, Rosen L. Mosquito vectors and dengue virus vector relationships. In: Gubler DJ, Kuno G, editors. Dengue and Dengue Hemorrhagic Fever. New York: CAB International; 1997. p. 4560.

4. Bhatia R, Dash AP, Sunyoto T. Changing epidemiology of dengue in South-East Asia. WHO South-East Asia J Public Health 2013;2:23-7. https://doi.org/10.4103/22243151.115830
5. Gubler DJ. The changing epidemiology of yellow fever and dengue, 1900 to 2003: Full circle? Comp Immunol Microbiol Infect Dis 2004;27:319-30. https://doi.org/10.1016/ j.cimid.2004.03.013

6. Guzman MG, Halstead SB, Artsob H, Buchy P, Farrar J, Gubler DJ, et al. Dengue: A continuing global threat. Nat Rev Microbiol 2010;8 (12 Suppl):S7 16. https://doi.org/10.1038/ nrmicro2460

7. Sangkawibha N, Rojanasuphot S, Ahandrik S, Viriyapongse S, Jatanasen S, Salitul V, et al. Risk factors in dengue shock syndrome: A prospective epidemiologic study in Rayong, Thailand. Am J Epidemiol 1984;120:653 69. https://doi.org/ 10.1093/oxfordjournals.aje.a113932

8 Ooi EE, Gubler DJ. Dengue in South East Asia: Epidemiological. characteristics and strategic challenges. Cad Saude Publica 2008;25 Suppl 1:S115 24. https://doi.org/ 10.1590/S0102-311X2009001300011 